\title{
Sciendo
}

\section{EFFECT OF LAYING HEN GENOTYPE, AGE AND SOME INTERIOR EGG QUALITY TRAITS ON LYSOZYME CONTENT*}

\author{
Józefa Krawczyk ${ }^{1 \bullet}$, Lidia Lewko², Jolanta Calik ${ }^{1}$ \\ 'Department of Poultry Breeding, National Research Institute of Animal Production, \\ 32-083 Balice n. Kraków, Poland \\ ${ }^{2}$ Experimental Station Kołuda Wielka, Waterfowl Genetic Resources Station in Dworzyska, \\ National Research Institute of Animal Production, 62-035 Kórnik, Poland \\ •Corresponding author: jozefa.krawczyk@iz.edu.pl
}

\begin{abstract}
The objective of the study was to evaluate the quality of eggs laid by native breed hens of different ages ( 33 and 53 weeks of age), with particular consideration of the lysozyme parameters. Eggs were collected from 6 breeds/strains of laying hens under the genetic resources conservation in Poland, i.e. Greenleg Partridge (Z-11), Yellowleg Partridge ( $\dot{Z}-33)$, Rhode Island Red (R-11), Rhode Island White (A-33), Sussex (S-66) and Leghorn (H-22). The yolks of eggs from older hens had a more favourable, intense colour, but the freshness parameters (albumen height and Haugh units) of these eggs were lower. The albumen of eggs from older hens showed greater content and higher enzymatic activity of lysozyme in both thin and thick albumen. Among the six strains of hens, lysozyme content and enzymatic activity were highest in the egg albumen of strains $\dot{Z}-33$, Z-11 and R-11, and lowest in that of strain H-22. The analysed eggs showed statistically significant correlations between some interior egg quality traits (albumen weight, albumen height, Haugh units, yolk colour) and the discussed enzyme parameters. These traits are influenced by genotype and age of the hens.
\end{abstract}

Key words: egg quality, lysozyme, native breeds of hens

Table eggs are a valuable component of the daily human diet, and they include readily available protein, vitamins, and a variety of trace elements (Anton et al., 2006). Albumen, which forms around 58-64\% of the egg's weight, contains between 78 and 189 different proteins (Mann, 2007; Mann and Mann, 2011; Bilkova et al., 2018) as well as lysozyme, which shows antibacterial activity, especially against Gram-positive bacteria (Kovacs-Nolan et al., 2005; Trziszka et al., 2007; Abeyrathne et al., 2013; Miranda et al., 2015; Tomczyk et al., 2016). This enzyme is a natural

*Work financed from statutory activity, project no. 501-120-811. 
protective barrier of the egg contents against microorganisms, and its bacterial action involves hydrolysis of 1,4- $\beta$-glycosidic bonds between $\mathrm{N}$-acetylmuramic acid and $\mathrm{N}$-acetylglucosamine of the polysaccharide that builds the bacterium's cellular wall (Leśnierowski and Borowiak, 2012).

Lysozyme, which accounts for around 3.5\% of albumen protein in hen egg, $1.2 \%$ in duck egg, $0.6 \%$ in goose egg and only around $0.3 \%$ in pheasant, is the interior egg's natural barrier against microorganisms (Cegielska-Radziejewska et al., 2008; Kijowski et al., 2013; Nowaczewski et al., 2013). These properties of lysozyme are widely used in the pharmaceutical and food industries (Gajda and Bugla-Płoskońska, 2014; Salejda and Krasnowska, 2014). Studies are underway to increase lysozyme activity in the egg albumen under the influence of temperature, water, alcohol, sugars, acid solutions and other chemicals, and to develop drug formulations on the basis of lysozyme (Cegielska-Radziejewska et al., 2008). Kowalska et al. (2020) found that replacement of soybean with narrow-leaved lupin in hen diets had no significant effect on changes in lysozyme level. In pheasant eggs, Nowaczewski et al. (2013) observed lysozyme content and activity in egg albumen to be higher in light- than dark-shelled eggs.

Bilkova et al. (2018) and Gvoždíková Javůrková et al. (2019) reported that there is a relationship between some quality traits of eggs and their lysozyme and ovotransferrin concentrations in native and ornamental breeds of Czech hens. The authors noted that the eggs from native and ornamental breeds of hens have a high potential for use where food safety is a priority. In Poland, the genetic resources conservation programme includes 11 strains of hens, which have since the 1970 s been kept in small populations (800-1100 birds) subjected to no selection for production traits or egg quality. Krawczyk and Calik (2018) observed high variation for most egg quality traits in native breeds of hens. Krawczyk (2009) noted that the percentage of albumen in eggs from native breed hens is significantly lower than in the eggs from commercial hybrids used in intensive egg production. Calik (2016), who studied chemical composition of eggs from some strains of hens, found egg albumen content to increase with the age of layers. The hens whose eggs are studied have not been selected for production and egg quality traits because the main objective of the programme is to preserve the hens' genotype and to protect them from increased inbreeding. A significant effect of bird age was also reported by Zita et al. (2009), Tůmová and Gous (2012), Padhi et al. (2013), Tůmová et al. (2014).

Many authors point out that in native populations and in wild birds subjected to no selection, the level of different valuable nutrients in eggs is highly dependent on egg quality traits (Myint et al., 2012; Kinoshita et al., 2016). It is therefore interesting to investigate lysozyme parameters in the albumen of eggs from Polish conserved breeds of hens. After analysing the results of many international studies, it was hypothesized that in this large population of hens under conservation in Poland, not selected for many years, interior egg quality traits are highly related to the level of valuable lysozyme. This enzyme is one of the most valuable natural substances, which likely has a greater potential than has been identified, and hen's egg albumen is the only source from which it can be obtained on a commercial scale. Because lysozyme is highly important to various branches of the industry, the study results 
may be useful in the programmes for genetic improvement of laying hens aimed to improve egg quality traits, including lysozyme content and activity. In addition, the present research will allow choosing strains of hens with a higher lysozyme content of eggs. The results of the study should make it easier to select eggs with a higher lysozyme content, which, due to its bactericidal properties may be a determining factor in selection of eggs by the consumers.

The objective of the study was to evaluate the quality of eggs produced by native breed hens of different ages, with particular consideration of the level and activity of lysozyme. The study will answer which of the studied strains of native hens lays eggs with the highest lysozyme content and determine the effect of layer age on this egg quality trait.

\section{Material and methods}

The study material consisted of eggs collected from 6 breeds/strains of laying hens included in the conservation programme in Poland, i.e. Greenleg Partridge (Z-11), Yellowleg Partridge (Ż-33), Rhode Island Red (R-11), Rhode Island White (A-33), Sussex (S-66) and Leghorn (H-22). Birds were kept on an experimental farm, each strain in 4 replications with 30 birds per replication, totalling 720 hens. Hens were raised in the litter housing system at a stocking density of 5 birds $/ \mathrm{m}^{2}$ and fed a standard DJ layer diet with ad libitum access to feed and water. The diet contained $89.11 \%$ dry matter, $11.28 \%$ crude ash, $16.93 \%$ crude protein, $2.15 \%$ crude fat, $2.5 \%$ crude fibre, $3.55 \%$ calcium and $0.5 \%$ phosphorus.

At 33 and 53 weeks of age, 28 eggs (7 per replicate) were randomly collected from each breed of hens. After $24-\mathrm{h}$ refrigerated storage at $4^{\circ} \mathrm{C}$ and $55 \%$ humidity, eggs were subjected to quality assessment using EQM system (Egg Quality Measurements, TSS QCS-II). This instrument was used to determine the weight of different egg fractions, albumen height, and Haugh units. The $\mathrm{pH}$ values of albumen (on whole egg white) and yolk were determined with a portable pH-meter (Seven2Go, Mettler-Toledo). The albumen and yolk water content was determined by the drying method according to PN-A-86509 (1994). Egg shape index (\%) was calculated by dividing egg length by egg width. Measurements were made to the nearest $0.5 \%$ with a Shape-Meter (B.V. Apparatenfabriek Van Doorn, De Bilt, The Netherlands), scaled $65-85 \%$.

For detailed analysis of the active substance in the egg albumen fractions, i.e. lysozyme (hydrolytic activity, percentage), 28 eggs collected and weighed beforehand were broken, and their contents were separated into albumen and yolk. Egg albumen was fractionated into thick and thin albumen and spilled into disposable sterile containers. Then, prepared egg albumen samples were used to make appropriate preparations to determine lysozyme content and hydrolytic activity in albumen fractions. The content and activity of lysozyme in the fresh albumen fractions, was determined spectrophotometrically (Leśnierowski and Kijowski, 1995) based on the lysis of cell walls of Micrococcus lysodeikticus bacteria. Lysis effects are seen in re- 
duced opacity of the bacterial suspension, which is recorded spectrophotometrically through measurement of the absorbance of the studied suspension, prior to adding lysozyme and 1 minute after enzyme addition. Hydrolytic activity of lysozyme was expressed in lysozyme activity units $(\mathrm{U} / \mathrm{ml})$. One such unit is defined as the amount of lysozyme that in one minute decreases the absorbance of a Micrococcus lysodeikticus bacterial suspension by 0.001 , measured at a wavelength of $450 \mathrm{~nm}$ and a temperature of $25^{\circ} \mathrm{C}$. The reaction occurred in a mixture of a volume of $2.6 \mathrm{ml}$ ( $2.5 \mathrm{ml}$ of bacterial suspension $+0.1 \mathrm{ml}$ lysozyme solution) and $\mathrm{pH} 6.24$, in a cuvette with a length of optical path being $1 \mathrm{~cm}$. Lysozyme solution was made by dissolving $1 \mathrm{mg}$ of lysozyme (hen's egg albumen lysozyme - Sigma-Aldrich) in fresh distilled water, transferring it to a measuring flask and filling with distilled water up to $50 \mathrm{ml}$. After calculating the value of absorbance decrease $(\Delta \mathrm{A})$ for the working solution of lysozyme, a curve of correlations between $\Delta \mathrm{A}$ and lysozyme concentration was graphed. Next, based on the standard curve, hydrolytic activity of lysozyme was determined in the studied preparations. The value of the decrease in the solution absorbance $(\triangle \mathrm{A})$ was calculated from the following equation:

$$
\Delta A=A t O-A t(U / m i n .)
$$

where:

AtO - absorbance value for bacterial suspension at time t0,

$A t$ - absorbance value for bacterial suspension after time t.

Data were processed using Statistica 13.1 PL software. Mean values for all analysed parameters were calculated. A two-way model of ANOVA was used to analyse variability (variable 1: genotype; variable 2: week). The significance of differences was verified using Duncan's test. Interactions between experimental variables were assessed. The significance of differences was set at $\mathrm{P} \leq 0.05$ and $\mathrm{P} \leq 0.01$. Pearson's coefficients of correlation were also calculated between the analysed traits.

\section{Results}

Highly significant differences $(\mathrm{P} \leq 0.01)$ were observed in the interior egg quality traits between the hen strains and between the age of layers (Tables 1-3). The increasing age of the hens was paralleled in all strains by decreases in the shape index (by 2.4 percentage points on average), albumen height (by $1.57 \mathrm{~mm}$ on average) and Haugh units (by 15.2 on average), and by increases in the other traits. The egg shape index was similar in all strains, ranging from 75.7 (S-66) to $76.9 \%(\mathrm{R}-11)$ for younger layers, and from 73.1 (R-11) to $74.8 \%$ (A-33) for older birds, but the differences were not significant. Except for the shape index, albumen height and Haugh units, all the egg quality traits were at the same time influenced by genotype and age. At both 33 and 53 weeks of age, lighter weight eggs were laid by Z-11 and S-66 layers, and largest eggs by H-22 hens (Table 1). At 33 weeks of age, heaviest yolks were found 
in strains H-22, Ż-33 and A-33, and lightest yolks in strain S-66 (Table 2). At 53 weeks, largest yolks were noted in strains H-22 and Ż-33 and smallest yolks in strain S-66. At 33 weeks, the most intense yolk colour occurred for R-11 hens, and the least intense for H-22 birds. In older layers, yolk colour intensity leveled off among the strains, increasing in all the groups except Ż-33 and R-11. Highest yolk acidity (lowest $\mathrm{pH}$ value) in eggs laid at 33 and 53 weeks was observed in strain $\dot{Z}-33$. In all the strains, yolk $\mathrm{pH}$ value increased with age and the highest increase occurred in strains $\mathrm{H}-22$ and A-33. Water content was lowest in Z -33 and R-11 yolks and highest in egg yolks from $\mathrm{H}-22$ and $\mathrm{A}-33$ hens.

Regardless of age, the most favourable results for albumen quality, i.e. highest albumen height and Haugh units, were observed in the eggs of R-11 hens, and the least favourable in strain A-33 (Table 3). In strain R-11, despite the increasing albumen $\mathrm{pH}$ level with the age of layers, this trait was significantly $(\mathrm{P} \leq 0.01)$ lower at both 33 and 53 weeks compared to the other strains. In all strains except for $\dot{Z}-33$ and S-66, albumen weight increased significantly with age and with increasing egg weight, but regardless of age, average albumen weight was lowest for strains Z-11, Ż-33 and S-66, and highest for strain H-22. High and statistically significant differences were observed between the strains in egg yolk $\mathrm{pH}$ and in albumen water content. Regardless of age, the highest $\mathrm{pH}$ value on average was found in egg albumen from $\dot{Z}-33$ and A-33 hens. The highest water content was noted in egg albumen from H-22, R-11 and A-33 hens and this trait was influenced by bird age, bird genotype, and simultaneously by both factors.

Both hen genotype and age had a highly significant effect on the content and hydrolytic activity of lysozyme. At the same time, these two factors only had an effect on the activity of this enzyme in thick albumen (Table 4). Thin albumen from the eggs of R-11 birds showed, on average, the highest lysozyme percentage and thus the highest enzymatic activity of $71726 \mathrm{U} / \mathrm{ml}$. In turn, the lowest percentage was noted in the albumen of H-22 eggs, where lysozyme percentage averaged 0.293 and its activity was $62757 \mathrm{U} / \mathrm{ml}$. Analysis of lysozyme in thick albumen showed that the albumen of eggs from Z-11 birds was characterized not only by highest percentage $(0.218 \%)$ but also by highest enzymatic activity of lysozyme (47 011 $\mathrm{U} / \mathrm{ml}$ ). The lowest values of these parameters, similar to the thin albumen fraction, were obtained for the egg albumen of H-22 birds. Lysozyme content and activity in both thick and thin albumen showed a significant increase with the age of the hens $(\mathrm{P} \leq 0.001)$.

As is evident from Table 5, the eggs showed a significant negative correlation between lysozyme content in thin albumen and albumen height, Haugh units, and with yolk water content, and a positive correlation with albumen weight. Lysozyme content in thick albumen was negatively correlated with albumen weight and height, Haugh units, and yolk weight, and positively correlated with yolk colour. Lysozyme activity in thin albumen was negatively correlated with albumen weight, albumen height, Haugh units, and yolk water content, and positively correlated with yolk colour. Lysozyme activity in thick albumen was negatively correlated with albumen weight and albumen $\mathrm{pH}$, and positively correlated with yolk weight and colour. 


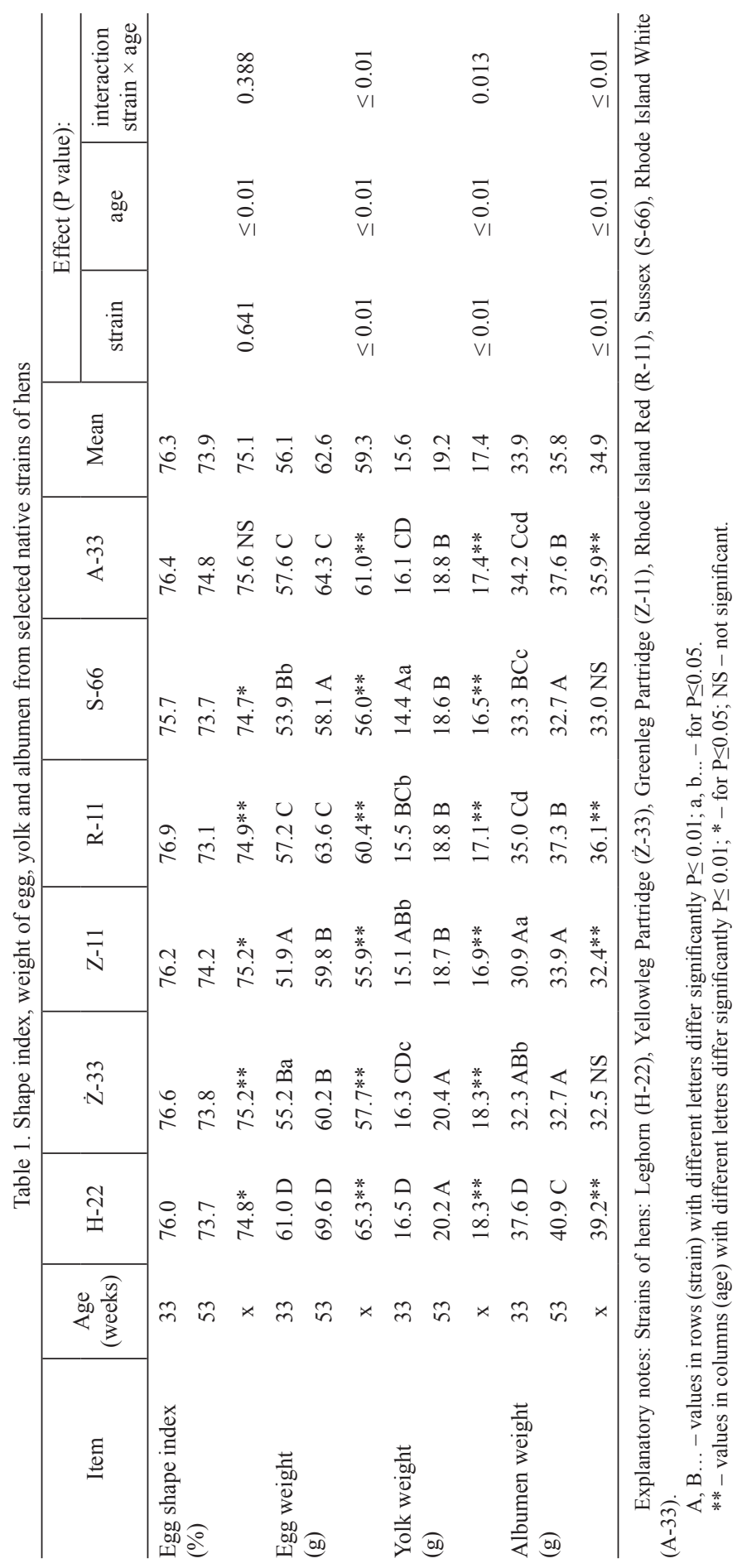




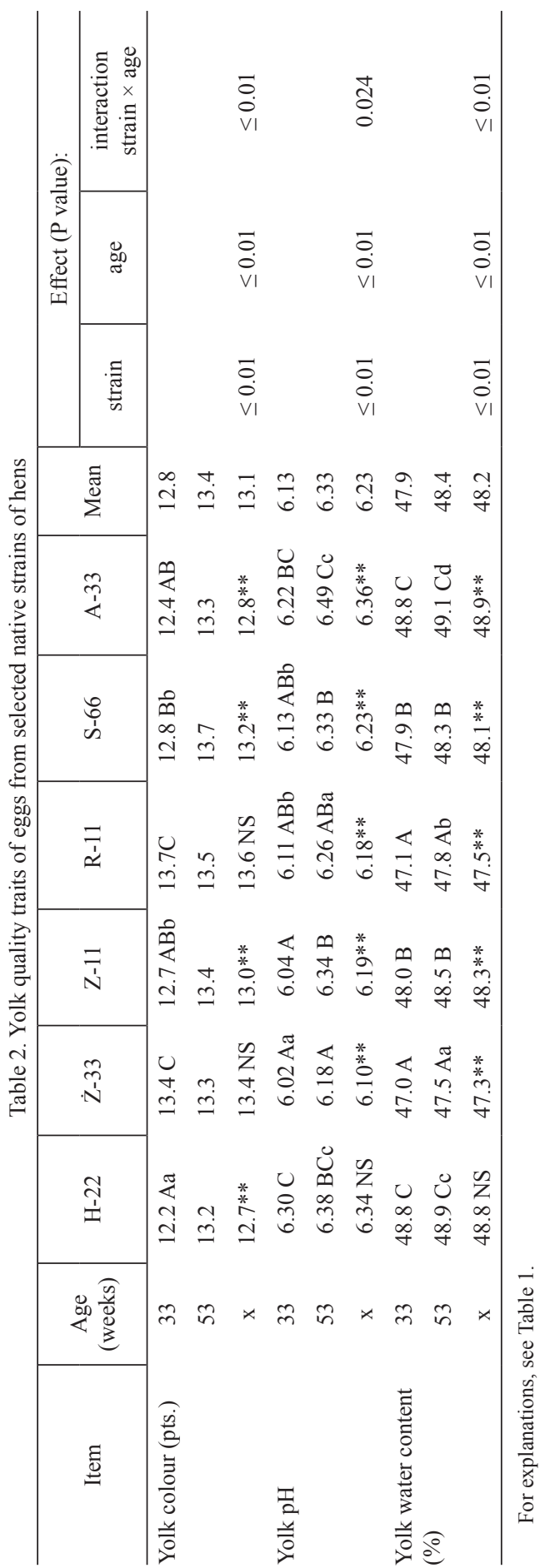




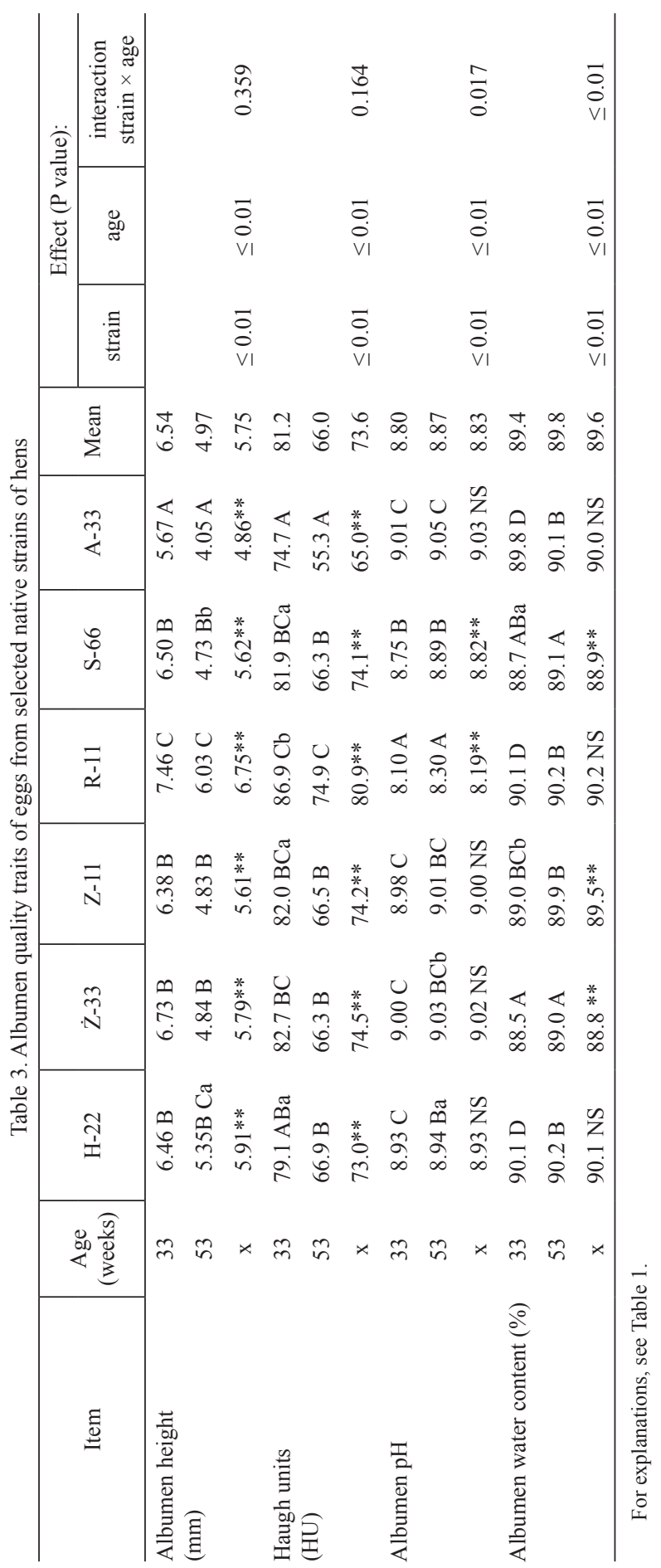




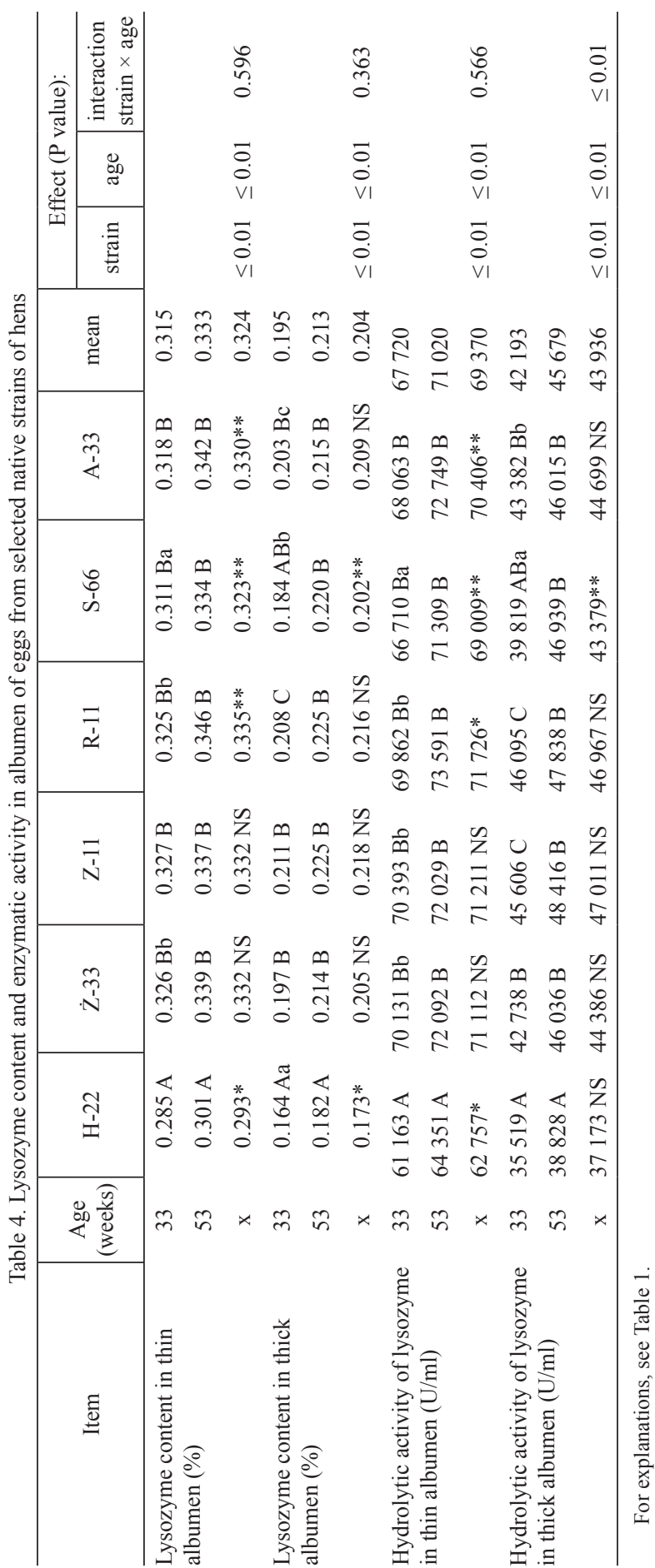




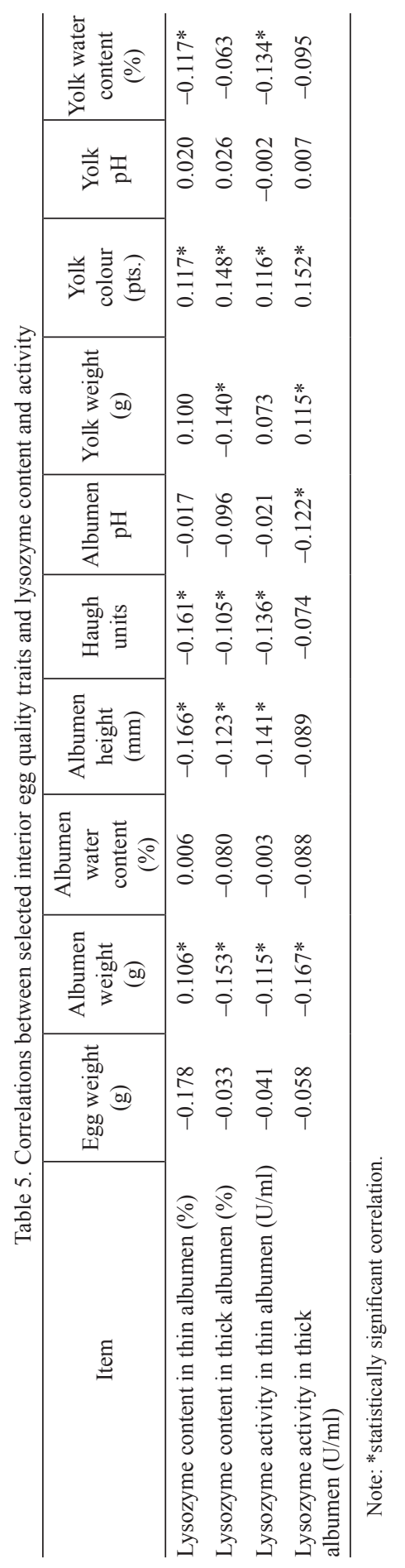




\section{Discussion}

In our study we found large, statistically significant differences in the egg quality traits of the studied strains of hens under conservation in Poland. Our findings are consistent with those of Krawczyk (2009) and Krawczyk and Calik (2018) and show the biodiversity of the conserved breeds. It is a widely known relationship that the weight of egg, yolk and albumen increases with the age of hens. The average albumen weight in strains H-22, R-11 and A33 was significantly higher than in the other hens and comparable to the domestic commercial hybrids investigated by Lewko and Gornowicz (2009, 2015), but lower than for the eggs of Hy-line commercial hybrids (Rizzi and Marangon, 2012). Egg albumen weight was found to be significantly correlated to lysozyme percentage and lysozyme activity. Many studies have shown that increasing egg weight with hen's age translates into increased albumen percentage, and such a relationship allows concluding a positive relationship between hen's age and egg lysozyme content and activity.

Egg yolk colour is an important marketing factor. Consumers prefer dark yellow colour, and yolk colour intensity depends mainly on the hen's diet, and indirectly on the rearing system (Sokołowicz et al., 2018; Kowalska et al., 2020). Our research showed that yolk colour intensity improves as laying hens become older. Because the hens in our study were not exposed to different feeding and rearing systems, it seems that this increase in yolk colour intensity in older hens results from enhanced absorption of carotenes from cereals fed over a prolonged period, and the results obtained are in agreement with those of Czaja and Gornowicz (2006) and Krawczyk (2009). The presence of a positive relationship between yolk colour and lysozyme content may provide important information for consumers that the eggs from the studied breeds of hens, with darker yolk colour, also have a higher lysozyme content, which is indicative of many health-promoting properties.

The higher the albumen height and Haugh units, the fresher the egg is, and this trait is mainly influenced by storage conditions and, as follows from our study, by the age of the hens. Our research also showed a relationship in that some egg quality traits deteriorated with age, which was also reported by other authors (Calik, 2011; Krawczyk and Calik, 2018; Vlčková et al., 2019; Kowalska et al., 2020). In our study, regardless of bird genotype, eggs from young layers exhibited significantly higher Haugh units and albumen height, which is indicative of their better quality. The differences in these traits between the hen strains are consistent with the results of Krawczyk and Calik (2018) and Banaszewska et al. (2019). Moreover, we found lower albumen water content in the eggs from older hens, while Czaja and Gornowicz (2006) reported an inverse relationship in commercial hybrids.

Alkalization of the egg contents has a considerable impact on albumen structure, and maintenance of its gel structure is determined by the lysozyme-ovomucin interaction. According to Trziszka et al. (2007), this relationship is most lasting when pH is around 8.0, whereas Salejda and Krasnowska (2014) demonstrated that enzymatic stability of lysozyme activity is maintained for $\mathrm{pH}$ of 5.3-6.0. In our study, the average $\mathrm{pH}$ of albumen ranged from 8.1 to 9.03 and was close to the results of similar studies with eggs from different breeds of hens (Trziszka et al., 2007; Rizzi 
and Marangon, 2012), but in our study the enzymatic activity in both thin and thick albumen was much lower. A higher level of lysozyme in the albumen of eggs from commercial layer hybrids, compared to our study, was also reported by Lewko and Gornowicz (2015). In the study by Banaszewska et al. (2019), lysozyme activity in the eggs of Ross 308 broilers was considerably lower than in our study.

Among the 6 breeds of native hens, eggs from strains Z-11, Z-33 and R-11 were characterized by significantly higher content and activity of lysozyme in the egg albumen. It should be highlighted that these 3 strains of hens have remained unselected for production traits since the late 1960s, which is earlier than for the other strains, and were the first to be included in the conservation programme. Myint et al. (2012) and Kinoshita et al. (2016) observed the different antimicrobial potential of commercial bird strains subjected to artificial selection on pedigree farms, in terms of the biological activity of hatching eggs. Therefore they suggested that in the native populations and in wild birds, the level of various valuable egg components is highly dependent on their quality traits. It follows from the study of Gvoždíková Javůrková et al. (2019) with eggs from 41 fancy and conserved breeds of hens that in free-living native breeds of hens, the level of lysozyme and ovotransferrin in egg albumen is greatly determined by environmental conditions (temperature, humidity), genotype, diet, and laying season. Lewko and Gornowicz (2010), who studied eggs from 7 strains of hens in a domestic pedigree farm, observed significant negative correlations between the $\mathrm{pH}$ level of egg albumen and lysozyme in only two strains. We found negative correlations only between $\mathrm{pH}$ of egg albumen and lysozyme activity in thick albumen, and lysozyme content and activity were more affected by albumen weight, albumen height, Haugh units and yolk colour. A search of literature revealed that egg lysozyme content and activity is not significantly related to yolk colour, which may suggest the randomness of this relationship in our experiment. These traits are influenced by both hen genotype and age, which means that these factors indirectly affect lysozyme content and activity. Banaszewska et al. (2019), who studied the eggs of broiler breeder hens, observed a significant increase in lysozyme activity in the eggs from older hens, which is consistent with our study. In turn, Kowalska et al. (2020) reported that diet compared to hen's age had a greater effect on this trait.

\section{Conclusions}

There was an increase in lysozyme content of egg albumen, and thus in its hydrolytic activity in thin and thick albumen with increasing age of the hens.

Among the six strains, the content and hydrolytic activity of lysozyme in both analysed egg albumen fractions was highest in Ż-33, Z-11 and R-11 hens, and lowest in $\mathrm{H}-22$ birds.

The present study showed that in order to obtain lysozyme from native hen eggs, it is more effective to use eggs from older hens, especially those of the $\dot{Z}-33, \mathrm{Z}-11$ and R-11 strains. Considering the health benefits of lysozyme, eggs with higher lysozyme content and activity are also more attractive to consumers.

The analysed eggs showed statistically significant correlations between some interior egg quality traits (albumen weight, albumen height, Haugh units, yolk colour) and the discussed enzyme parameters. These relationships also allow consumers 
to identify eggs with higher lysozyme content among purchased eggs. These traits are influenced by genotype and age of the hens.

\section{References}

Abeyrathne E.D.N.S., L e e H.Y., Ahn D.U. (2013). Egg white proteins and their potential use in food processing or as nutraceutical and pharmaceutical agents - a review. Poultry Sci, 92: 3292-3299.

A n t on M., N a u F., Nys Y. (2006). Bioactive egg components and their potential uses. World. Poultry Sci. J., 62: 429-438.

B an a szewska D., B i es i d a - Drzazga B., Ostrowski D., Drabik K., B a tkow ska J. (2019). The impact of breeder age on egg quality and lysozyme activity. Turkish J. Anim. Sci., 43: 583-589.

B il kova B., Sw i derska Z., Zit a L., La loe D., Charles M., B en es V., S to pka P., Vink l e r M. (2018). Domestic fowl breed variation in egg white protein expression: Application of proteomics and transcriptomics. J. Agr. Food Chem., 66: 11854-11863.

C a li k J. (2011). Assessing the quality of eggs produced by six breeds of egg-laying hens in relation to their age (in Polish). Żywn. Nauka Technol. Jakość, 5: 85-93.

C a li k J. (2016). Assessment of content of selected chemical components in hen eggs depending on their production cycle (in Polish). Żywn. Nauka Technol. Jakość, 3: 54-63.

Cegielska-Radziejewska R., Leśnierowski G., Kijowski J. (2008). Properties and application of egg white lysozyme and its modified preparations - a review. Polish J. Food Nutr. Sci., 58: 5-10.

C zaja L., Gornowicz E. (2006). The effect of the genome and age of hens on the quality of table eggs (in Polish). Ann. Polish Soc. Anim. Prod., 33: 59-70.

Gaj d a E., B u g la - P ło s k oń s k a G. (2014). Lysozyme - occurrence in nature, biological properties and possible applications (in Polish). Postepy Hig. Med. Dosw., 68: 1501-1515.

Gvoždíková Javůrková V., Pokorná M., Mikšik I., T ůmová E. (2019). Concentration of egg white antimicrobial and immunomodulatory proteins is related to eggshell pigmentation across traditional chicken breeds. Poultry Sci., 98: 6931-6941.

Kijowski J., Leśnierowski G., Cegielska-Radziejewska R. (2013). Chicken eggs: source of valuable bioactive components (in Polish). Żywn. Nauka Technol. Jakość, 5: 29-41.

Kinoshita K., Myint S.L., Shimogiri T., Ibrahim H.R., Kawabe K., Okamoto S., L e e Y.P., Mats uda Y., M ard a Y. (2016). Chicken ovotransferrin variants OTFB and OTFC harboring substitution of GAT (Asp) to AAT (Asn) in the codon 500 and their antimicrobial activity. J. Poultry Sci., 53: 257-263.

Kovacs-Nolan J.K.N., Phillips M., Mine Y. (2005). Advances in the value of eggs and egg components for human health. J. Agric. Food Chem., 53: 8421-8431.

Kowalska E., Kucharska-Gaca J., Kuźniacka J., Lewko L., Gornowicz E., Bie s e k J. A d a m s ki M. (2020). Quality of eggs, concentration of lysozyme in albumen, and fatty acids in yolk in relation to blue lupin-rich diet and production cycle. Animals, 10: 735-775.

K r a w c z y k J. (2009). Effect of layer age and egg production level on changes in quality traits of eggs from hens of conservation breeds and commercial hybrids. Ann. Anim. Sci., 9: 185-193.

K r a w c z y k J., C a li k J. (2018). Quality assessment of eggs laid by hens included in programmes for the conservation of animal genetic resources (in Polish). Food Sci. Technol. Quality, 25: 140-150.

L eś n i e r o w s k i G., K i j o w s k i J. (1995). Methods for testing enzymatic activity and quantification of lysozyme from chicken egg protein (in Polish). Przem. Spoż., 49: 476-479.

L eśn i e r ow s k i G., B or ow i a k R. (2012). Effect of environmental conditions on change in properties of lysozyme in hen egg white (in Polish). Żywn. Nauka Technol. Jakość, 19: 77-87.

L ew ko L., Gornowicz E. (2009). Egg albumen quality as affected by bird origin. J. Cent. Eur. Agric., 10: 455-463.

Lew k o L., Gornowi c z E. (2015). Bird nutrition - possibilities of modifying the quality of hen's egg with consideration of lysozyme properties (in Polish). Wiad. Zoot., RLIII: 16-24.

Ma n n K. (2007). The chicken egg white proteome. Proteomics, 7: 3558-3568. 
Mann K., Mann M. (2011). In-depth analysis of the chicken egg white proteome using an LTQ Orbitrap Velos. Proteome Sci., 9: 7.

Miranda J.M., Anton X., Redondo-Valbuena C., Roca-Saavedra P., Rodrig u e z J.A., L a m a s A., Fr a n c o C.M., C e p e d a A. (2015). Egg and egg-derived foods: effects on human health and use as functional foods. Nutrients, 7: 706-729.

Myint S.L., Kinoshita K., Shimogiri T., Ibrahim H.R., Tsusaki T., Tanoue T., K a w a b e K., M a e d a Y., O k a m o t o S. (2012). Effect of polymorphism in egg white lysozyme on muramidase and antibacterial activities as well as hatchability in the Japanese quail (Coturnix japonica). J. Anim. Sci., 90: 1747-1755.

Nowaczewski S., Szablewski T., Cegielska-Radziejewska R., Stuper-Szablewska K., Rudzińska M., Leśnierowski G., Kontecka H., Szulc K. (2013). Effect of housing system and eggshell colour on biochemical and microbiological characteristics of pheasant eggs. Arch. Geflugelkd., 77: 226-233.

P a d h i M.K., Chat terje e R.N., Ha un sh i S., R a j k u mar U. (2013). Effect of age on egg quality in chicken. Indian J. Poultry Sci., 48: 122-125.

Rizzi C., Marang on A. (2012). Quality of organic eggs of hybrid and Italian breed hens. Poultry Sci., 91: 2330-2340.

S a le j d a A.M., Kras now s k a G. (2014). Bioactive compounds of hen egg - possibilities of application in biopreservation of meat and meat products (in Polish). Bromat. Chem. Toksykol., XLVII: $72-81$.

Sokołowicz Z., Krawczyk J., Dykiel M. (2018). Effect of alternative housing systems and hen genotype on egg quality characteristics. Emir. J. Food Agr., 30: 696-703.

Tomczyk Ł., Szablewski T., Cegielska-Radziejewska R. (2016). Nutritional value of table eggs originating from laying hens kept under different housing systems (in Polish). Żywn. Nauka Technol. Jakość, 6: 20-27.

Trziszka T., Dobrzański Z., Skiba T., K o peć W. (2007). Effect of breeding and housing systems of layers on egg quality and the activity of cystatin and lysozyme. Pol. J. Food Nutr. Sci., 57: 583-586.

T ůmová E., G o u s R.M. (2012). Interaction of hen production type, age, and temperature on laying pattern and egg quality. Poultry Sci., 91: 1269-1275.

T ůmová E., Gou s R.M., Tyle r N. (2014). Effect of hen age, environmental temperature, and oviposition time on egg shell quality and egg shell and serum mineral contents in laying and broiler breeder hens. Czech J. Anim. Sci., 59: 435-443.

Vlčk ová J., T ůmová E., Mík ová K., Englmai e rová M., Okrouhlá M., Chodová D. (2019). Changes in the quality of eggs during storage depending on the housing system and the age of hens. Poultry Sci., 98: 6187-6193.

Z i t a L., T ům o vá E., Š t o l c L. (2009). Effects of genotype, age and their interaction on egg quality in brown-egg laying hens. Acta Vet. Brno, 78: 85-91.

Received: 16 VI 2020

Accepted: 17 XI 2020 